\title{
Applicability of Nixtamalization in the Processing of Millet-based Maasa, a Fermented Food in Ghana
}

\author{
James Owusu-Kwarteng ${ }^{1} \&$ Fortune Akabanda ${ }^{1}$ \\ ${ }^{1}$ Department of Applied Biology, Faculty of Applied Sciences, University for Development Studies, Navrongo, \\ Ghana
}

Correspondence: James Owusu-Kwarteng, Department of Applied Biology, Faculty of Applied Sciences, University for Development Studies, P. O. Box 24, Navrongo, Ghana. Tel: 233-209-265-738. E-mail: jowusukwarteng@yahoo.co.uk

Received: October 25, 2012 Accepted: December 11, 2012 Online Published: January 15, 2013

doi:10.5539/jfr.v2n1p59 URL: http://dx.doi.org/10.5539/jfr.v2n1p59

\begin{abstract}
Maasa is a spontaneously fermented millet-based fried cake in Ghana. Nixtamalization, a process of cooking and soaking cereals (usually maize) in lime solution, was applied in the traditional processing of the Ghanaian millet-based fermented maasa. During the processing, Lime cooked millet dough (LCMD) and water soaked millet dough (WSMD) samples were analyzed for proximate composition, $\mathrm{pH}$, total titratable acidity and microbial counts were assessed for fermenting millet dough samples. Finally, maasa prepared from nixtamalized and non-nixtamalized fermented millet dough samples were assessed for consumer sensory acceptability on a five-point hedonic scale. Nixtamalization improved crude protein and ash contents of millet dough samples whereas fat and fiber contents decreased. During fermentation, a reduction in $\mathrm{pH}$ and increase in total titratable acidity was observed for both nixtamalized and non-nixtamalized millet dough samples. Lactic acid bacteria (LAB) and yeasts count reached 9.4 and $8.0 \mathrm{logcfu} / \mathrm{g}$ respectively for non-nixtamalized millet after 14 hours of fermentation, whereas for nixtamalized millet samples, LAB and yeasts count reached 7.6 and $7.5 \mathrm{logcfu} / \mathrm{g}$ respectively. Consumer sensory evaluation of Maasa produced from nixtamalized fermented millet had improved texture, colour and overall acceptability as compared to the traditional non-nixtamalized fermented millet-based maasa. Nixtamalization can thus be applied in the production of Ghanaian millet-based maasa to improve nutritional quality and acceptability as well as maintain the benefits associated with traditional cereal fermentation.
\end{abstract}

Keywords: nixtamalization, fermentation, millet, maasa, lime cooking, consumer acceptability

\section{Introduction}

Millet being an important cereal in Africa and Asia, is used primarily for human food and remains a major source of calories and a vital component of food security in the developing world (FAO, 1996). Through fermentation, achieved by the metabolic activities and/or enzymes endogenous to the raw materials, millet and other cereals processing may contribute to the development of characteristic properties such as taste, aroma, visual appearance, texture, shelf life, and safety (Hammes, 1990). In Ghana, millet is processed into various foods including koko (Lei \& Jakobsen, 2004), fura (Owusu-Kwarteng et al., 2012), and maasa. Maasa is a millet-based spontaneously fermented cake. Maasa is popularly consumed as an adjunct to breakfast porridges throughout Ghana, with similar products consumed in parts of West Africa (Nkama, 1993). The widespread use and dependence on millet as a staple in tropical Africa, coupled with its low nutritive value has necessitated the need to investigate simple traditional methods of processing geared towards improving the quality and acceptability of millet-based foods.

Nixtamalization, a traditional process of lime cooking and steeping of cereals, particularly maize, is popular in Mexico and Central America, and has been practiced for many years (Bressani et al., 1990; Serna-Saldivar et al., 1990; Martínez-Flores et al., 2002; 2006; Rendón-Villalobos et al., 2009). During nixtamalization, many physical (Rodriguez et al., 1996; Almeida-Dominguez et al., 1997), structural (Parades-Lopez and Saharopulos, 1982; Gomez et al., 1989), and chemical (Bedolla \& Rooney, 1982; Morad et al., 1986; Serna-Saldivar et al., 1988) changes are known to occur inside the cereal grains. These changes may include the solubilization and dissolution of pericarp tissues, especially at the endocarp layer, partial starch gelatinization in the endosperm, partial protein denaturation in both the endosperm and the germ, hydration of starch and protein molecules, and 
penetration and absorption of calcium into the endosperm and germ matrices. These changes lead to softened, swollen kernels that can be readily ground via attrition milling during processing. Other benefits associated with nixtamalization include increased bioavailability of niacin, improved protein quality, increased calcium content and the reduction of aflatoxin concentrations (Serna-Saldivar et al., 1987; Wall \& Carpenter, 1988; Bressani et al., 1990; Sefa-Dedeh et al., 2004; Ayala-Rodriguez et al., 2009).

The purpose of this study therefore, was to assess the influence of nixtamalization on the proximate composition, fermentation characteristics and consumer acceptability of Ghanaian fermented millet-based cake, maasa.

\section{Materials and Methods}

\subsection{Raw Materials}

The local variety of pearl millet (Pennisetum glaucum) was purchased from a local retail outlet in Navrongo market, Ghana. They were cleaned and stored at ambient temperature $\left(29 \pm 1{ }^{\circ} \mathrm{C}\right)$ until they were used.

\subsection{Preparation of Maasa Samples}

The traditional process of maasa preparation (non-nixtamalization) involved steeping $1 \mathrm{~kg}$ of clean millet grains in $2 \mathrm{~L}$ de-mineralized water for $12 \mathrm{~h}$. After steeping, the millet grains were washed and excess water drained off. For nixtamalized millet-based maasa preparation, $1 \mathrm{~kg}$ of clean millet grains were cooked in $1 \%(\mathrm{w} / \mathrm{v})$ lime solution $\left[\mathrm{Ca}(\mathrm{OH})_{2}\right]$ for 30 minutes and then steeped in the cooked liquor for $12 \mathrm{~h}$. After steeping, the samples were washed thoroughly (twice) with distilled water to remove residual lime and extraneous pericap materials. The subsequent processing steps were the same for both nixtamalized and the non-nitamalized millet grains (Figure 1). After draining, the grains were milled using a plate attrition mill (model: $\mathrm{N}^{\mathrm{o}} 2 \mathrm{~A}$ - Amuda grinding mill) to obtain a wet milled dough. The dough samples were then divided into two portions of two-thirds $(2 / 3)$ and one-third (1/3). The $1 / 3$ portion was used to prepare a $30 \%(\mathrm{w} / \mathrm{v})$ slurry, cooked into a pre-gelatinized meal and mixed with the $2 / 3$ portion to obtain a thick paste. The mixture was then allowed to spontaneously ferment for 14 $\mathrm{h}$. The fermented paste was then fried (in portions of about $100 \mathrm{ml}$ ) in oil for approximately $5 \mathrm{~min}$ to obtain either a traditional non-nixtamalized or nixtamalized millet-based cake (maasa) (Figure 1).

\subsection{Proximate Analysis of Nixtamalized and Non-nixtamalized Millet Dough Samples}

Proximate composition on dry matter basis was determined according to the AOAC (2000) methods. Crude protein content was determined using the Kjeldahl method (Method 960.52) $(\mathrm{N} \times 5.83$ ). Crude lipid content was determined using the Soxhlet extraction method (Method 920.39C). Ash content was determined by heating the dried sample in a furnace at $550^{\circ} \mathrm{C}$ (Method 923.03). Carbohydrate content was calculated by difference. All analysis was carried out in triplicates.

\section{$2.4 \mathrm{pH}$ and Total Titratable Acidity}

The $\mathrm{pH}$ values of nixtamalized and non-nixtamalized millet samples were determined using a $\mathrm{pH}$ meter (Crison Basic, model 20) according to approved method 44-19 (AACC, 2000). The pH meter was calibrated at room temperature with three different buffers (standard buffers $\mathrm{pH} 4$, 7, and 10). Ten (10) g sample was placed in a beaker containing $100 \mathrm{ml}$ of distilled water $(10 \% \mathrm{w} / \mathrm{v}$ slurry) and stirred for $15 \mathrm{~min}$ to homogenize the sample. The resulting suspension was left to stand for $15 \mathrm{~min}$, and the $\mathrm{pH}$ level was read in the supernatant liquid. Ten-milliliter aliquots of filtrates of the slurry were titrated against $0.1 \mathrm{~N} \mathrm{NaOH}$ standard solution to determine the total titratable acidity.

\subsection{Isolation and Enumeration of Microorganisms}

Duplicate $10 \mathrm{~g}$-samples of fermenting millet dough were homogenized with $90 \mathrm{ml}$ sterile peptone physiological saline solution ( $5 \mathrm{~g}$ bactopeptone, $8.5 \mathrm{~g} \mathrm{NaCl}, 1000 \mathrm{ml}$ distilled water, $\mathrm{pH} 7.0 \pm 0.2$ ). The homogenate was serially diluted to the $10^{-9}$ concentration and $0.1 \mathrm{ml}$ aliquots of the dilutions directly inoculated by surface plating on various isolation media. Lactic acid bacteria were isolated on MRS agar (Merck, Darmstadt, Germany). Plates were incubated anaerobically (BBL gas pack, Anaerocult A, Merck) at $30^{\circ} \mathrm{C}$ for $48 \mathrm{~h}$. Aerobic mesophilic bacteria were enumerated on Plate count agar (PCA) (Oxoid Ltd, Basingstoke, Hampshire, England), pH 7.0 and incubated at a temperature of $32^{\circ} \mathrm{C}$ for $48 \mathrm{hrs}$. Sabourand Dextrose Agar (Merck), supplemented with $250 \mathrm{mg} / 100 \mathrm{ml}$ chloramphenicol (selective supplement, Oxoid) with $\mathrm{pH}$ adjusted to 3.5 with tartaric acid was used for the isolation and enumeration of yeasts. Inoculated plates were incubated at $25^{\circ} \mathrm{C}$ for 5 days. Following incubation, the number of colony forming units (CFU) per gram of sample was determined using a digital colony counter and recorded.

\subsection{Consumer Sensory Evaluation of Maasa Samples}

The final products (massa) prepared from nixtamilized and non-nixtamilized millet were served to 25 untrained 
panel (drawn from the Faculty of Applied Sciences of the University for Development Studies) who are familiar with massa. The panel evaluated the two products for their sensory qualities (taste, colour, odour, texture and overall acceptability) using a five-point hedonic scale ( 1 and 5 representing extremely dislike and like respectively). The judges were made to wash their mouth with water after evaluating each product.

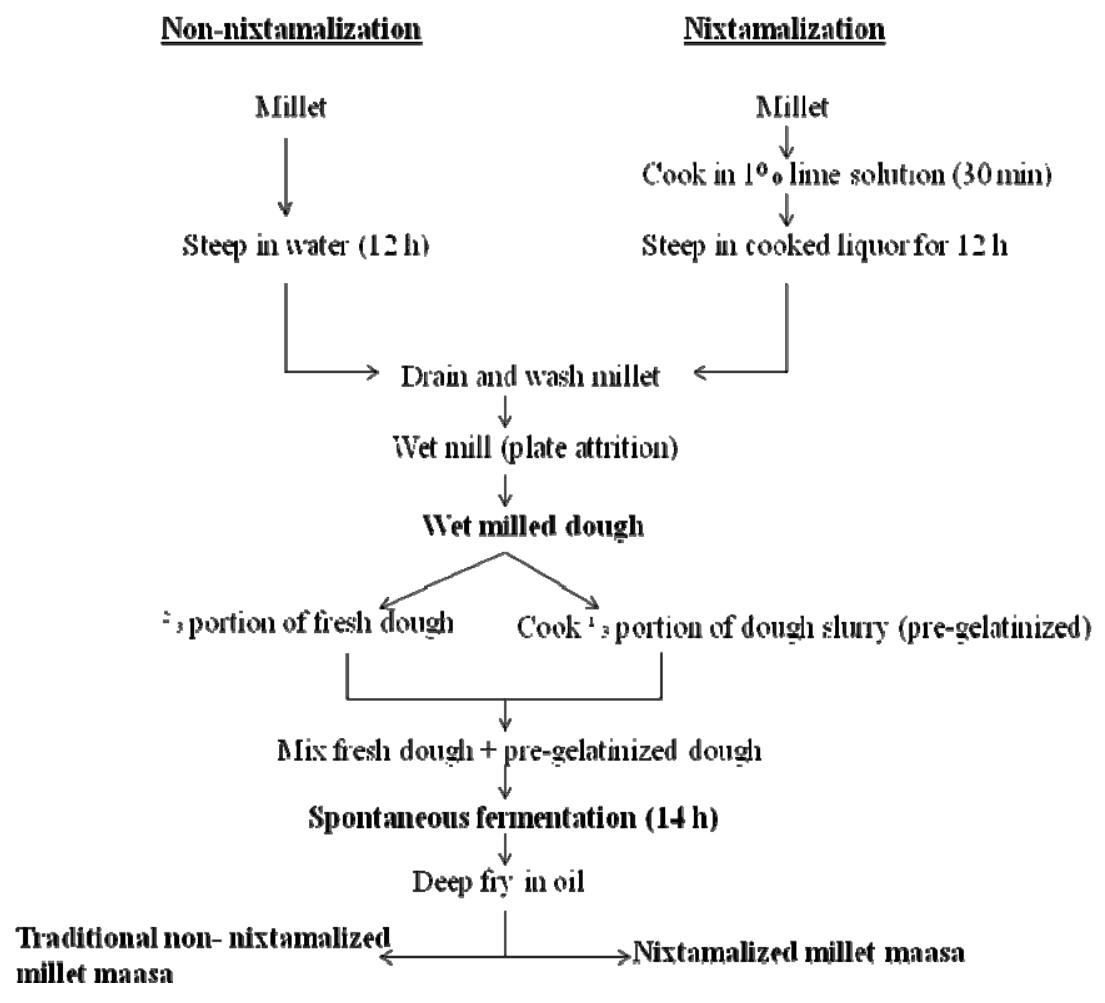

Figure 1. Process for production of nixtamalized and non-nixtamalized millet-based maasa

\section{Results and Discussion}

\subsection{Proximate Composition}

Proximate composition of lime cooked millet dough (LCMD; nixtamalized millet) and water steeped millet dough (WSMD; non-nixtamalized millet) is presented in Table 1. Crude protein content was higher in the nixtamalized millet dough $(15.2 \pm 0.45 \%)$ as compared to the non-nixtamalized millet dough $(11.8 \pm 0.32 \%)$. Previous studies have reported increases in nitrogen content of lime cooked cereal grains and have attributed the observation to concentration effect. Nixtamalization may lead to removal of soluble starch and thereby increasing the relative percentage of proteins. Bressani et al. (1958) reported that protein content of maize increased from $9.6 \%$ to $10.3 \%$ when maize was nixtamalized. Similarly, Gomez et al. (1987) and Serna-Saldivar et al. (1987) also reported an increase in the amount of protein when alkaline cooked corn products were compared to the original grain. Sefa-Dede et al. (2004) also observed a slight increase in protein content from $8.14 \%$ in raw maize sample to $8.88 \%$ in maize samples cooked for $30 \mathrm{~min}$ in lime solution. The same study further observed increasing protein content with increasing lime concentration used for nixtamalization. Significant increase in crude protein content of nixtamalized millet flour has also been reported by Ocheme et al. (2010).

Nixtamalized millet dough had reduced fat content of $4.4 \pm 0.18 \%$ as compared to $5.7 \pm 0.24 \%$ for non-nixtamalized millet dough samples, an observation that could be attributed to elevated temperatures during lime cooking and metallic ions $\left(\mathrm{Ca}^{2+}\right)$ contributed by lime solution, facilitating fats oxidation and degradation (Charley \& Weaver, 1998).

Crude ash contents was higher in nixtamalized millet dough than in non-nixtamalized millet dough samples (Table1). Increased ash content in nixtamalized millet samples is perhaps a result of $\mathrm{Ca}^{2+}$ ion absorbed into the grains during lime cooking and steeping. Serna-Saldívar et al. (1991) reported that the amounts of lime 
remaining in the grain are mainly the result of cooking and steeping. Studies have established some link between dietary calcium intake and diseases such as osteoporosis, arterial hypertension and colon cancer (Muñoz-Chávez et al., 1995), and although these diseases may have many causes, calcium intake may help in their prevention (Trejo-Gonzalez et al., 1996). The average recommended dietary allowance (RDA) of calcium is about 800-1200 mg per day, depending on the country. In developed countries, about $70 \%$ of dietary calcium comes from milk and dairy products with a few vegetables considered to be good sources of calcium. However, the calcium intake from dairy products in developing countries such as Ghana is limited by the high cost of milk and other dairy products and some vegetables. Therefore, incorporating lime cooking (nixtamalization) and soaking into traditional cereals processing to increase calcium intake would be an advantage for many developing countries including Ghana.

Nixtamalized millet samples had reduced contents of crude dietary fiber than the corresponding non-nixtamalized millet samples (3.6\% and $4.1 \%$, respectively), which corresponds with previous studies on nixtamalized and non-nixtamalized corn (Bressani et al., 1990; 2001). The decrease in fiber content may be attributed to the removal of pericarp during nixtamalization (Bressani et al., 1990; Serna-Saldívar et al., 1990; Paredes-López et al., 2000). Total carbohydrates content was reduced in nixtamalized millet dough (74.3 \pm $0.65 \%$ ) as compared to $76.6 \pm 0.80 \%$ for non-nixtamalized millet dough. Since carbohydrate content was determined by difference, it is obvious that variations in the other proximate compositions would affect the total carbohydrate content.

Table 1. Proximate composition of nixtamalized and non-nixtamalized millet dough

\begin{tabular}{llllll}
\hline Sample & protein & fat & ash & fiber & carbohydrate \\
\hline LCMD & $15.2 \pm 0.45$ & $4.4 \pm 0.18$ & $2.5 \pm 0.04$ & $3.6 \pm 0.05$ & $74.3 \pm 0.65$ \\
WSMD & $11.8 \pm 0.32$ & $5.7 \pm 0.24$ & $1.8 \pm 0.01$ & $4.1 \pm 0.15$ & $76.6 \pm 0.80$
\end{tabular}

Key: LCMD: lime cooked millet dough; WSMD: water steeped millet dough.

\subsection{Fermentation Characteristics}

Fermentation characteristics of nixtamalized and non-nixtamalized millet dough samples is shown in Table 2 . Initial $\mathrm{pH}$ of WSMD was $5.54 \pm 0.16$ and dropped to $3.85 \pm 0.05$ whereas the $\mathrm{pH}$ of LCMD dropped from $8.12 \pm 0.05$ to $4.45 \pm 0.08$ after $14 \mathrm{~h}$ of fermentation. The high initial $\mathrm{pH}$ of nixtamalized millet dough sample was due to the alkaline soaking and cooking. $\mathrm{pH}$ reduction was observed with a concomitant increase in total titratable acidity in both nixtamalized and non-nixtamalized millet dough samples. Sefa-Dedeh et al. (2003) reported that the $\mathrm{pH}$ of nixtamalized corn decreased with fermentation time reaching a value of 4.13 after $72 \mathrm{~h}$. The decrease in $\mathrm{pH}$ and the corresponding increase in titratable acidity is a relevant aspect of fermented cereals as they influence sensory characteristics and safety, particularly in Africa. It therefore implies that alkaline cooking can be combined with fermentation during millet-based maasa without negatively affecting sensory and safety characteristics of the final product. LAB counts increased from $6.5 \pm 0.25$ to $9.4 \pm 0.18 \operatorname{logcfu} / \mathrm{g}$ and $4.4 \pm 0.4$ to $7.6 \pm 0.34 \mathrm{logcfu} / \mathrm{g}$ for non-nixtamalized and nixtamalized millet dough samples respectively. Similarly, Yeasts counts and total bacterial counts increased with fermentation time (Table 2). This implies that the predominant microorganisms often associated with spontaneous African cereal fermentations (Halm et al., 1993; Lei \& Jakobsen, 2004; Owusu-Kwarteng et al., 2012 ) may not be significantly affected by the nixtamalization process since $\mathrm{LAB}$ and yeasts were isolated in large numbers during the fermentation processes for both nixtamalized and non-nixtamalized millet dough samples. The possible effects such as bacteriocins production, probiotic characteristics, safety and improved texture exerted by these microorganisms in cereal fermentation may as well be achieved. 
Table 2. Fermentation characteristics of nixtamalized and non-nixtamalized fermenting millet dough

\begin{tabular}{cccc}
\hline $\begin{array}{l}\text { Fermentation } \\
\text { characteristics }\end{array}$ & $\begin{array}{c}\text { Fermentation time } \\
\text { (hours) }\end{array}$ & WSMD & LCMD \\
\hline pH & 0 & $5.54 \pm 0.16$ & $8.12 \pm 0.05$ \\
& 14 & $3.85 \pm 0.05$ & $4.45 \pm 0.08$ \\
TTA & 0 & $0.15 \pm 0.04$ & $0.01 \pm 0.08$ \\
& 14 & $0.42 \pm 0.03$ & $0.25 \pm 0.10$ \\
LAB (logcfu/g) & 0 & $6.5 \pm 0.25$ & $4.4 \pm 0.40$ \\
& 14 & $9.4 \pm 0.18$ & $7.6 \pm 0.35$ \\
Yeasts (logcfu/g) & 0 & $5.2 \pm 1.15$ & $4.3 \pm 0.60$ \\
& 14 & $8.0 \pm 0.30$ & $7.5 \pm 1.30$ \\
TBC (logcfu/g) & 0 & $7.3 \pm 0.54$ & $7.0 \pm 0.95$ \\
& 14 & $8.5 \pm 0.86$ & $8.2 \pm 0.66$ \\
\hline
\end{tabular}

Key: LCMD: lime cooked millet dough; WSMD: water steeped millet dough.

\subsection{Consumer Sensory Analysis}

Consumer sensory evaluation of maasa prepared from nixtamalized (LCMM) and non-nixtamalized (WSMM) fermented millet is shown in Figure 2. For taste, non-nixtamalized millet-based maasa had an average score of $3.3 \pm 0.95$ as compared to $3.2 \pm 0.98$ for nixtamalized millet-based maasa. For all other sensory attributes (odour, colour, texture and overall acceptability), nixtamalized millet-based maasa had higher average score as compared to the non-nixtamalized millet-based maasa. The taste of nixtamalized millet based fermented maasa was negatively affected possibly due to the high $\mathrm{pH}$ and low acidity. Traditional non-nixtamalized fermented millet-based maasa is associated with low $\mathrm{pH}$ and acidic taste. Colour and texture were however greatly improved with nixtamalization, perhaps due to the removal of extraneous pericap materials during washing after lime cooking and soaking. Hydration of the millet grains during the alkaline cooking process is important because it is the means through which calcium ions penetrate into the millet grain during the cooking and steeping in the nixtamalization process. In these phases of cooking and steeping, hydration and partial gelling of the grain starches occur simultaneously, along with the diffusion of calcium ions, which determine the physicochemical and sensorial properties of the final product.The combined improvements in texture, odour and colour of nixtamalized fermented millet-based maasa resulted in an overall acceptability comparable to the traditional non-nixtamalized millet-based maasa.

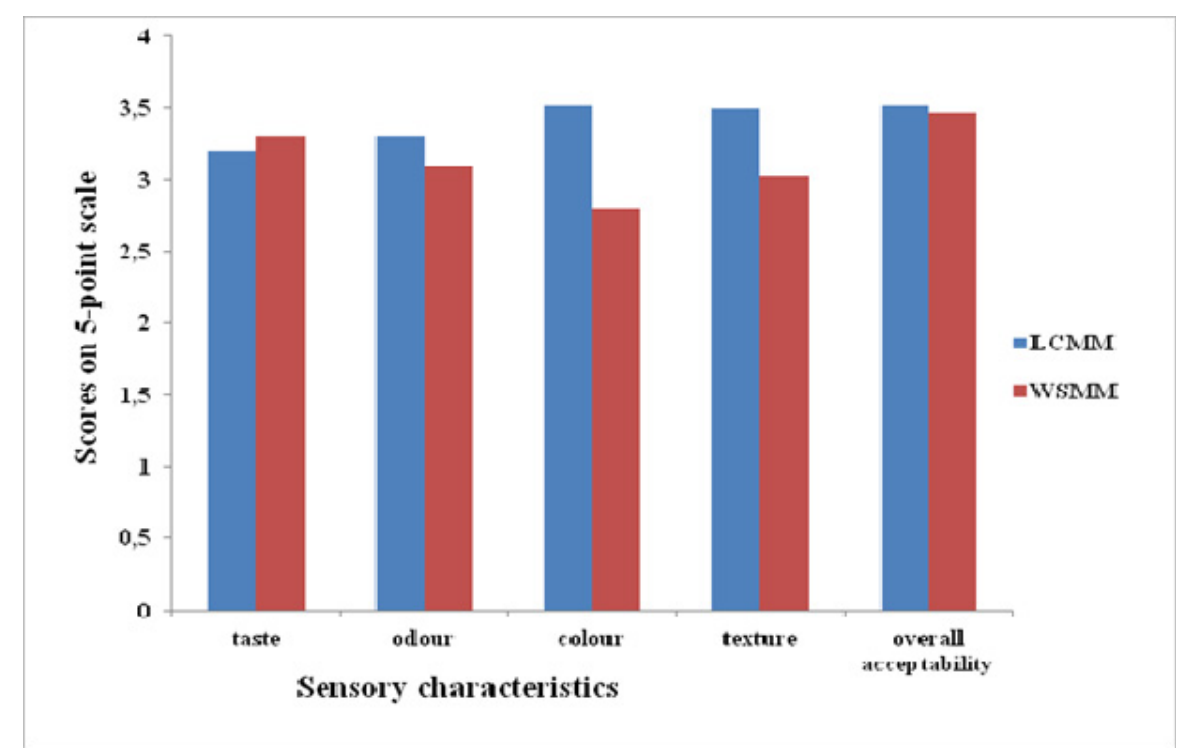

Figure 2. Consumer sensory evaluation of nixtamalized (LCMM) and non-nixtamalized (WSMM) fermented millet-based maasa 


\section{Conclusion}

Nixtamalization, a process of cooking and steeping corn in $1 \%$ lime solution, has successfully been applied to millet for the production of Ghanaian maasa. The process yielded maasa of acceptable quality to consumers.

\section{Acknowledgements}

The work was carried out at the UDS/DANIDA microbiology laboratory, University for Development Studies, Navrongo, Ghana. Alberta Mensah is acknowledged for helping with data collection.

\section{References}

AACC. (2000). Approved methods 08-01, 30-25 and 46-13. American Association of Cereal Chemists, St. Paul, $\mathrm{MN}, \mathrm{USA}$.

AOAC. (2000). Official Methods of Analysis of AOAC International, 17th ed. AOAC. Gaithersburg, MD, USA.

Ayala-Rodriguez, A. E., Gutierrez-Dorado, R., Milan-Carrillo, J., Mora-Rochin, S., López-Valenzuela, J. A., \& Valdez-Ortiz, A. (2009). Nixtamalized flour and tortillas from transgenic maize (Zea mays L.) expressing amarantin: Technological and nutritional properties. Food Chem., 114, 50-56. http://dx.doi.org/10.1016/j.foodchem.2008.09.017

Bedolla, S., \& Rooney, L. W. (1982). Cooking maize for masa production. Cereal Foods World., 27, 219-221.

Bressani, R., Benavides, V., Acevedo, E., \& Ortiz, M. A. (1990). Changes in selected nutrient content and in protein quality of common and quality protein maize during tortilla preparation. Cereal Chem., 67, 515-518.

Bressani, R., Paz y Paz, R., \& Scrimshaw, N. S. (1958). Corn nutrient losses: chemical changes in corn during preparation of tortillas. J. Agric. Food Chem., 6, 770-774. http://dx.doi.org/10.1021/jf60092a009

Bressani, R., Turcios, J. C., Reyes, L., \& Mérida, R. (2001). Caracterización física y química de harinas industriales nixtamalizadas de maíz de consumo humano en América Central. Archivos Latinoamericanos De Nutricion, 51, 309-31.

Charley, H., \& Weaver, C. (1998). Foods - A scientific approach. Macmillan Publishers, London, UK.

FAO. (1996). Sorghum and millet in human nutrition. FAO Food and Nutrition Series. Trends and Outlook. Patencheru, Andhra Pradesh, India.

Gomez, M., Rooney, M., Waniska, L. W., \& Plugfelder, R. L. (1987). Dry corn (masa) flours for tortilla. Snack Foods World, 32, 372-377.

Halm, M., Lillie, A., Sørensen, A. K., \& Jakobsen. M. (1993). Microbiology and aromatic characteristics of fermented maize doughs for kenkey production in Ghana. Int. J. food microbiol., 19, 135-143. http://dx.doi.org/10.1016/0168-1605(93)90179-K

Hammes, W. P. (1990). Bacteria starter cultures in food production. Food Biotechnol., 4, 383-397. http://dx.doi.org/10.1080/08905439009549750

Lei, V., \& Jakobsen, M. (2004). Microbiological characterization and probiotic potential of koko and koko sour water, African spontaneously fermented millet porridge and drink. J. Appl. Microbiol., 96, 384-397. http://dx.doi.org/10.1046/j.1365-2672.2004.02162.x

Martínez-Flores, H. E., Garnica-Romo, M. G., Romero, V. J. U., \& Yahuaca, J. B. (2006). Evaluating the quality of lipids during alkaline cooking of corn. J. Food Lip., 13, 177-185. http://dx.doi.org/10.1111/j.1745-4522.2006.00043.x

Martínez-Flores, H. E., Martínez-Bustos, F., Figueroa, J. D. C., \& González-Hernández, J. (2002). Studies and biological assays in corn tortillas made from fresh masa prepared by extrusion and nixtamalization processes. J. Food Sci., 67, 1196-1199. http://dx.doi.org/10.1111/j.1365-2621.2002.tb09476.x

Morad, M. M., Iskander, F. Y., Rooney, L. W., \& Earp, C. F. (1986). Physicochemical properties of alkali-cooked corn using traditional and Pre-soaking procedures. Cereal Chem., 63, 255-259.

Muñoz-Chávez, M., Chávez, A., Valles, V., \& Roldan, J. A. (1995). The nopal: a plant of manifold qualities. In A. P. Simopoulos (Ed), Plants in Human Nutrition (World Review of Nutrition and Dietetics) (pp. 109-134). Basel, Switzerland: Karger Publishing.

Nkama, I. (1993). Studies on improving the Nutritional Quality of masa. Traditional fermented Cereal based food. A report. United Nations University, CFTRI, Mysore India.

Ocheme, B. O., Oloyede, O. O., \& Mikailu, E. G. (2010). Effect of lime soaking and cooking (nixtamalization) 
on the proximate, functional and some anti-nutritional properties of millet flour. AU J. T., 14, 131-138.

Owusu-Kwarteng, J., Akabanda, F., Nielsen, D. S., Tano-Debrah, K., Glover, R. L. K., \& Jespersen, L. (2012). Identification of lactic acid bacteria isolated during traditional fura processing in Ghana. Food Microbiol., 32, 72-78. http://doi:10.1016/j.fm.2012.04.010

Parades-Lopez, O., \& Saharopulos, M. E. (1982). Scanning electron miscroscopy studies of limed corn kernels for tortilla making. J. Food Technol., 17, 687-693. http://dx.doi.org/10.1111/j.1365-2621.1982.tb00228.x

Rendón-Villalobos, J. R., Bello-Pérez, L. A., Agama-Acevedo, E., Islas-Hernández, J. J, Osorio-Díaz, P., \& Tovar, J. (2009). Composition and characteristics of oil extracted from flaxseed-added corn tortilla. J. Food Sci., 53, 1391-1395.

Rodriguez, M. E., Yanez-Limon, M., Alvarado-Gil, J. J., Vargas, H., Sanchez-Sinencio, F., Figueroa, J. D. C., ... Miranda, L. C. M. (1996). Influence of the structural changes during alkaline cooking on the thermal, rheological, and dielectric properties of corn tortillas. Cereal Chem., 73, 593-600.

Sefa-Dedeh, S., Cornelius, B., \& Afoakwa, E. O. (2003). Effect of fermentation on the quality characteristics of nixtamalized corn. Food Res. Int., 36, 57-64. http://dx.doi.org/10.1016/S0963-9969(02)00108-4

Sefa-Dedeh, S., Cornelius, B., Sakyi-Dawson, E., \& Afoakwa, E. O. (2004). Effect of nixtamalization on the chemical and functional properties of maize. Food Chem., 86, 317-324. http://dx.doi.org/10.1016/j.foodchem.2003.08.033

Serna-Saldivar, S. O., Gomez, M. H., \& Rooney, L. M. (1990). Technology, chemistry, and nutritional value of alkaline-cooked corn products. Adv. Cereal Sci. Technol., 10, 243-306.

Serna-Saldivar, S. O., Knabe, D. A., Rooney, L. W., \& Tanksley, J. D. Jr. (1987). Effect of lime cooking on energy and protein digestibilities of maize and sorghum. Cereal Chem., 64, 247-252

Serna-Saldivar, S. O., Knabe, D. A., Rooney, L. W., Tanksley, T. D., \& Sproule, A. M. (1988). Nutritional value of sorghum and maize tortillas. J. Cereal Sci., 7, 83-94. http://dx.doi.org/10.1016/S0733-5210(88)80062-6

Serna-Saldivar, S. O., Rooney, L. W., \& Greene, L. W. (1991). Effects of lime treatment on the bioavailability of calcium in diets of tortillas and beans: growth/metabolic studies. Cereal Chem., 68, 565-570.

Trejo-Gonzalez, A., Feria Morales, A., \& Wild-Altamirano, C. (1982). The role of lime in the alkaline treatment of corn for tortilla preparation. In R. E. Feeney, \& J. R. Whitaker (Eds.), Modification of Proteins (pp. 245-263). Advances in Chemistry, Ser. No. 198. http://dx.doi.org/10.1021/ba-1982-0198.ch009

Wall, J. W., \& Carpenter, K. J. (1988). Variation in availability of niacin in grain products. Food Technol., 42, 198-204 